\title{
PROJETO COGNITIVO: UMA ABORDAGEM DO ENSINO DE PROJETO PELO INTERIOR DA PRÁTICA
}

\author{
PERDIGÃO, Ana Klaudia de Almeida Viana
}

Universidade Federal do Pará, e-mail: klaudiaufpa@gmail.com

\begin{abstract}
RESUMO
Investiga-se $\bigcirc$ projeto de arquitetura pela abordagem cognitiva. Inicia-se com a problematização sobre o ensino de projeto a qual vem sendo incorporada no desenvolvimento de pesquisa científica. Apresentam-se resultados de experimentações realizadas em sala de aula no primeiro ano de graduação em arquitetura e urbanismo. Objetiva-se discutir o aspecto cognitivo do projeto através da produção dos alunos e de suas falas sobre o próprio aprendizado. A metodologia de projeto adotada em sala de aula será tratada como processo ensino-aprendizagem nas avaliações das disciplinas PROJ I e II. O conjunto de resultados a ser observado se torna importante na medida em que promove a discussão combinada envolvendo a reflexão e a prática, por parte dos estudantes.
\end{abstract}

Palavras-chave: Projeto, Ensino, Cognição, Concepção.

\begin{abstract}
The architectural design is investigated by the cognitive approach. it begins with the problematization about the teaching of project that has been incorporated in the development of scientific research. We present results of experiments carried out in the classroom in the first year of graduation in architecture and urbanism. The objective is to discuss the cognitive aspect of the project through the production of the students and their speech about learning itself. the design methodology adopted in the classroom will be treated as a teaching-learning process in the evaluations of the proj I and II disciplines. The set of results to be observed becomes important in that it promotes the combined discussion involving reflection and practice on the part of the students.
\end{abstract}

Keywords: architectural design, teaching, research, cognition, conception.

\section{INTRODUÇÃO}

O projeto de arquitetura ainda encontra-se envolto a uma crise epistemológica que repercute no ofício da arquitetura e de seu ensino. A crise não é recente (COMAS, 1986). Contudo, mostra-se vulnerável quanto à transmissibilidade de competências e habilidades que elevariam a concepção arquitetônica ao seu devido lugar.

As transformações de paradigmas ao longo dos séculos sobre os modos de projetar demonstraram caminhos nem sempre lineares, muito pelo contrário, pactuados no decorrer da história como tradição da cultura arquitetônica no contexto das práticas, e assim superado, chega ao ponto em que ultrapassou o universo das práticas até à necessária caracterização, segundo Oliveira (2011), do projeto como objeto de conhecimento.

PERDIGÃO, A. K. A. V. Projeto cognitivo: uma abordagem do ensino de projeto pelo interior da prática. In: SIMPÓSIO BRASILEIRO DE QUALIDADE DO PROJETO NO AMBIENTE CONSTRUÍDO, 6., 2019, Uberlândia. Anais... Uberlândia: PPGAU/FAUeD/UFU, 2019. p. 1588-1598. DOI https://doi.org/10.14393/sbqp19143. 
A concepção e o desenvolvimento do projeto são momentos peculiares que envolvem diferentes capacidades para se chegar ao sucesso da solução. A investigação científica do processo de projeto pelo ponto de vista da caixa de vidro, conforme Jones (1971), permite uma interpretação do projeto tornandose explícito o conhecimento implícito (FLORIO, 2011), oportuniza a transparência nas decisões tomadas até a definição da solução arquitetônica.

Os métodos de projeto ainda não foram sistematicamente pesquisados e conhecidos pela comunidade científica, além de se mostrarem pouco presentes nos ateliers de ensino. Há muita produção bibliográfica com métodos interessantes mas que não se estabelecem como recomendações, são experiências isoladas, sem repercussões na área (KOWALTOWSKI e MOREIRA, 2015).

Desde a metade do Sec. XX, constata-se uma tendência internacional para o aprofundamento de investigações sobre procedimentos e métodos de projeto, cujo pioneirismo vem de universidades britânicas. No Brasil, o investimento em pesquisas projetuais ganha fôlego com a expansão da pósgraduação em universidades brasileiras para fazer face aos desafios do ensino de graduação, deixando para trás o método de tentativas e erros, ainda aplicado no ensino de graduação.

O conhecimento cognitivo e operativo passa a ser um pano de fundo para discussões profícuas a respeito da organização de bases teóricometodológicas para o ensino de projeto. Cabe à Philippe Boudon e ao seu LAREA, em 1975, um passo importante para explorar o que chama "espaço da concepção", pela compreensão das operações de concepção em jogo, quando o objeto é descrito através de categorias antes de ficar pronto.

A materialização da base cognitiva e operativa, como um aspecto transmissível da relação ensino-aprendizagem na disciplina de projeto, tornase possível pela explicitação de uma base teórico-metodológica capaz de instigar até às operações de projeto, ao domínio na formação seminal do pensamento projetual, à autonomia formada e que faz conduzir o próprio processo, a saber que 'aprender a fazer o projeto' primeiro, fundamenta o 'fazer o projeto,' (SILVA, 1986).

Nessa direção, exploram-se experimentações didáticas e testemunhos de alunos mediante às atividades desenvolvidas em sala ao discutir de um modo mais abrangente e profundo a adoção de métodos cada vez mais dinâmicos que passam a qualificar a concepção arquitetônica.

Destaca-se, uma didática adequada para o início da graduação em arquitetura e urbanismo na qual as condições para transformações ficam mais disponíveis.

\section{PROJETO COGNITIVO}

A escola de arquitetura ocupa-se da formação do estudante baseada em todos os processos que ensejarão na tomada de decisão arquitetônica. A problematização em torno do ensino de projeto tem levado à critica ao modo fragmentado com que os conteúdos são ministrados (Silva, 2003), o que ainda não foi superado. 
Quando defendia que aprender a fazer o projeto" antecede ao "fazer o projeto", Silva (1986) coloca no centro das atenções pedagógicas o aprendizado $\mathrm{m}$ vários níveis. O desenvolvimento de capacidades operativas sobre experimentações projetuais permitem a integração de conteúdos abrangentes por meio de um modo singular do pensamento.

Novo modos de pensar como o de Morin mostram-se inspiradores para 0 pensamento projetual. A organização do pensamento em torno da dualidade a ser enfrentada e que pode ser recomposta, mostra-se nas idas e vindas em torno da dependência existente entre o conhecimento das partes e do todo, na importância dos fenômenos multidimensionais evitando análises rígidas e limitadoras dos mesmos, no reconhecimento que a realidade dispõe de interpretação solidária ou conflitiva, acolhendo a diversidade ao mesmo tempo que existe unicidade (MORIN, 2000).

A prática do projeto é consequência de um pensamento projetual que requer um especial modo de observação, reflexão e ação (FRIGERIO et al., 2008). Portanto, o pensamento projetual antecede ao momento de definição da solução arquitetônica, motivo pelo qual o domínio cognitivo é fundamental no processo, além do conhecimento sobre o processo, através de mecanismos e instrumentos capazes de acelerar o amadurecimento de conteúdos e de operações de projeto.

O projeto é um processo complexo que envolve observar e interpretar a realidade, identificar oportunidades de intervenção, prefigurar cenários de transformação e testar suas condições de possibilidade. A essa condição do projeto, Fernandez (2010) chama de dimensão cognitiva do projeto.

Associa-se arcabouço teórico-metodológico aos procedimentos e soluções que sucedem a uma série de especulações, mediações, operações amparadas por um pensamento dinâmico e complexo. Um sistema de interpretação que foi se formando como um anseio de se integrar a vastos campos do conhecimento que passaram a avançar nos domínios das ciências cognitivas (CHUPIN, 2013).

Desse modo, adota-se o projeto cognitivo como estratégia para oportunizar uma prática profissional ensinável, como uma ponte didático-operativa que oferece tanto o entendimento no qual situa-se entre uma lógica de projeto tradicional ou não, quanto pelas novas exigências pautadas na complexidade da vida contemporânea.

A instrumentalização de capacidades mentais envolvendo conhecimento, habilidade e experiência (FLORIO, 2011), mostra-se fundamental e leva a caminhos inusitados com relação ao repertório e as associações possíveis na concepção arquitetônica. Uma abordagem humana pela cognição através da psicologia de Piaget (PIAGET E INHELDER, 1977), possibilita uma interpretação do processo de projeto por meio de operações associadas ao ciclo vital humano, melhor compreendidas pelo campo das representações espaciais.

Os períodos classificados por Piaget guardam especificidades no desenvolvimento humano com interesse para discussão no processo de projeto, ou seja, revelam aspectos do desenvolvimento biológico, e sua relação com o entorno, com implicações associadas a habilidades e competências do projetista na atuação profissional (THORNBERG, 1974). 
As representações espaciais no projeto de arquitetura (PERDIGÃO e BRUNA, 2009), seguem nessa direção como um passo para fundamentação de estudos de natureza projetual. A compreensão da concepção espacial baseada em capacidades relacionadas com a potencialidade de oferta física e cultural do ambiente, na qual é possível se cogitar a complexidade estrutural das relações espaciais, permite a observação do espaço arquitetônico como forma de representação de uma condição humana (CARPIGIANI e MINOZZI, 2002).

Apoiando-se na teoria cognitiva de Piaget, torna-se possível identificar a condição humana do projetista, acompanhando os processos cognitivos, deficitários ou não, conforme as capacidades requeridas nas atividades das disciplinas de projeto, entre análise, síntese e avaliação (BROADBENT e WARD, 1971), capacidades humanas acessadas na formação profissional.

O ensino de projeto funciona como laboratório para treinamento de habilidades e competências para análise e organização do espaço arquitetônico. Na sala de aula, a cada semestre encontra-se a oportunidade para o treinamento cognitivo-operativo, em modo crescente de amadurecimento do pensamento projetual, até alcançar o desempenho profissional à altura daquilo que é esperado para o arquiteto e urbanista.

As pesquisas sobre a teoria da produção arquitetônica relacionada ao projeto cognitivo, estão em curso no Laboratório Espaço e Desenvolvimento Humano da Universidade Federal do Pará. Os resultados de pesquisa são incontestáveis no alinhamento com a dimensão humana ${ }^{1}$ da arquitetura, entre aspectos da concepção arquitetônica e do uso espacial, do arquiteto e do usuário.

Considera-se a dimensão humana pela estreita ligação do ser humano com o que the rodeia, seja por meio dos sistemas sensoriais e atividades motoras (período sensório-motor), o conhecimento produzido pela capacidade de representação (período pré-operatório), o conhecimento produzido através de operações mentais (período operatório concreto) e, por fim, o conhecimento produzido pela organização de operações singulares em operações de ordem superior (período operatório formal), encontra-se latente e com potencial ligado à concepção arquitetônica, conforme Quadro 1.

A interpretação do processo de projeto através da teoria cognitiva permite a auto-avaliação continuada, seguindo Oliveira (2010), permite a interpretação pelo interior da prática do próprio processo de ideação e maturação dos conteúdos durante a elaboração do projeto de arquitetura. O processo ensino-aprendizagem torna possível a aproximação de saberes das diversas naturezas: sensorial, emocional e intelectual, sendo de grande relevância tornar mais explícitas questões da experiência, das habilidades e do conhecimento com os saberes envolvidos no ato de projetar.

\footnotetext{
1 Pesquisa intitulada a dimensão humana da arquitetura pela investigação de projeto no espaço habitacional: estudo de caso. Coordenação: Profa Dra Ana Klaudia de Almeida Viana Perdigão. Financiamento: Edital CNPq/CAPES N.07/2011. O estudo da dimensão humana da arquitetura se define nessa pesquisa ao situar o ser humano no centro das operações projetuais no exercício da prática arquitetônica. Para tanto, utiliza-se o espaço habitacional como recorte de pesquisa.
} 


\section{Quadro 1 - Períodos}

\begin{tabular}{|c|c|}
\hline Período & Característica \\
\hline $\begin{array}{l}\text { Sensório } \\
\text { Motor }\end{array}$ & $\begin{array}{l}\text { Período onde a memória elaborada não se manifesta, apenas a memória } \\
\text { afetiva, toda armazenada no inconsciente humano, acessada através de } \\
\text { sensações equivalentes, através dos registros corporais, do movimento e do } \\
\text { deslocamento no espaço, muitas vezes de difícil tradução em palavras pois é a } \\
\text { memória de um período onde não fazia parte do aparelho cognitivo humano a } \\
\text { linguagem. Desse modo, a interação com o meio circundante é } \\
\text { eminentemente sensorial. }\end{array}$ \\
\hline $\begin{array}{c}\text { pré- } \\
\text { operatório }\end{array}$ & $\begin{array}{l}\text { Refere-se à elação entre o objeto físico e a capacidade humana de } \\
\text { abstração, a capacidade de representar o que não comparece fisicamente } \\
\text { para nossos sentidos, quando fazer uma coisa representar algo diferente e que } \\
\text { não está presente", pensamos antes de atuar, o que passou a acontecer no } \\
\text { final do período anterior. A representação é algo de grande relevância para o } \\
\text { ser humano, com um registro importante nesse período. }\end{array}$ \\
\hline $\begin{array}{l}\text { período } \\
\text { operatório } \\
\text { concreto }\end{array}$ & $\begin{array}{l}\text { Momento do ciclo de desenvolvimento onde o ser humano aplica suas } \\
\text { operações mentais exclusivamente a objetos e eventos concretos. Uma } \\
\text { capacidade de grande importância para uma atuação profissional que } \\
\text { envolve dados de realidade, além de chamar por outras habilidades. }\end{array}$ \\
\hline $\begin{array}{c}\text { operatório } \\
\text { formal }\end{array}$ & $\begin{array}{l}\text { Transcende todas os períodos anteriores, quando o desenvolvimento } \\
\text { humano traz, consigo a capacidade de pensar sobre operações, além } \\
\text { de objetos. É capaz de transitar entre operações concretas e abstratas, } \\
\text { além de desenvolver a capacidade de produzir conhecimento de } \\
\text { modo sistêmico, ou seja, dinâmico e interativo. }\end{array}$ \\
\hline
\end{tabular}

\section{PROJETO COGNITIVO: O ENSINO}

No primeiro semestre do curso de graduação os estudantes são incentivados a exercitar a capacidade de análise e de síntese. Na primeira parte, a análise (CLARK e PAUSE, 1997; REIS, 2007) onde é desenvolvido o estudo da decomposição arquitetônica, há seleção de um arquiteto e uma obra para análise de temas geométricos e não geométricos ${ }^{2}$. Os arquitetos são contextualizados por períodos paradigmáticos da cultura arquitetônica, onde a história funciona como um filtro sobre o modo de elaboração do projeto. A análise da residência selecionada é apresentada na Figura 1, utilizando-se como exemplo um resultado de decomposição do discente Edenir Reis, calouro do ano de 2018 da FAU-UFPA.

Na segunda parte da disciplina, traça-se um paralelo com a obra analisada, levando-se a uma posterior associação com os elementos arquitetônicos mais marcantes e destacados pelo estudante na residência escolhida para a análise, sendo demonstrada a natural tendência do estudante para associar a concepção arquitetônica ao repertório mais imediato, no caso a residência analisada na decomposição, e não menos importante, portanto, já que integra um quadro de arquitetos e seus respectivos projetos emblemáticos.

\footnotetext{
${ }^{2}$ Aspectos geométricos e topológicos de uma edificação são descritos por Perdigão (2016).
} 


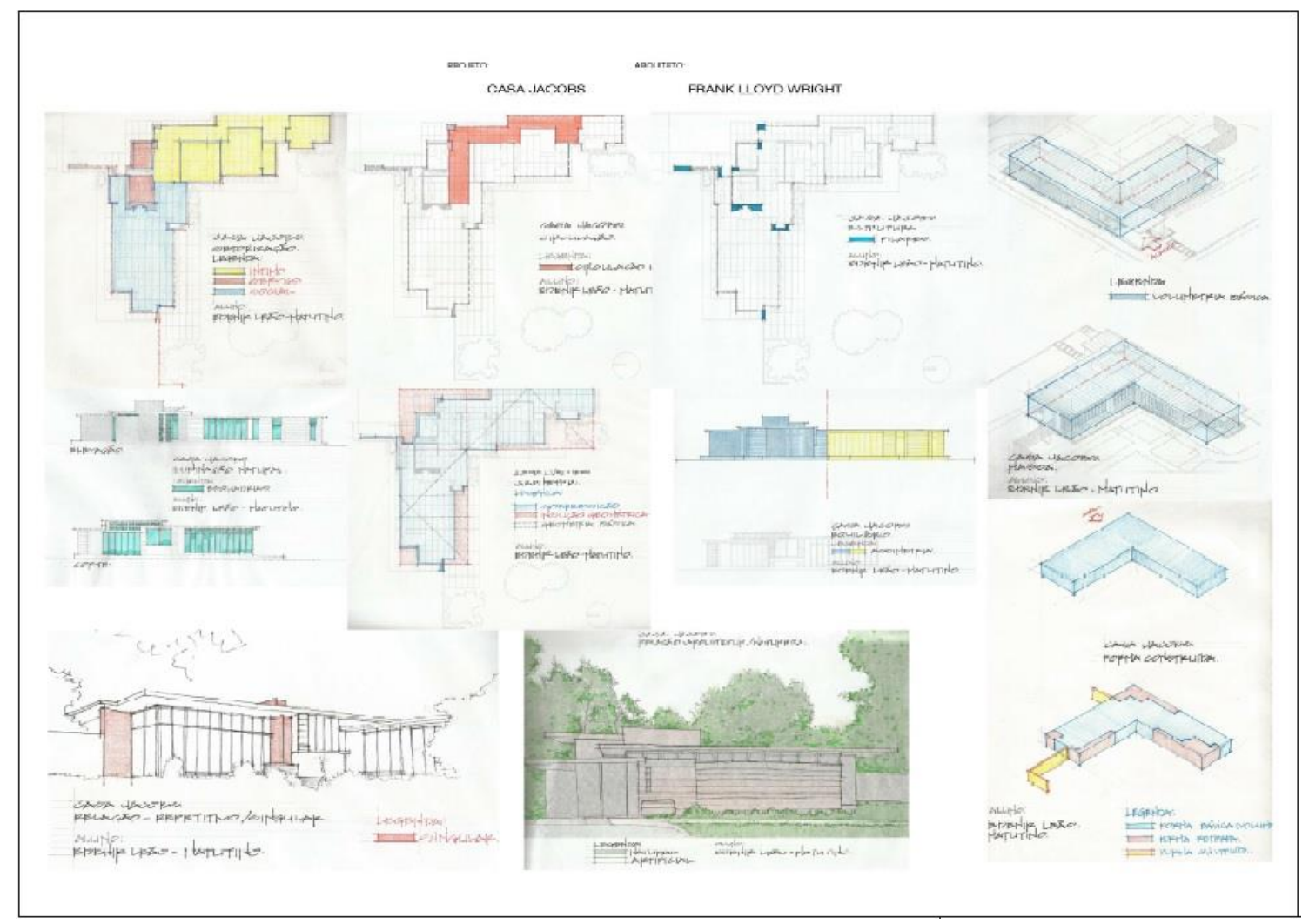

Figura 1 - Decomposição arquitetônica para treinamento de habilidades: análise Fonte: Disciplina Projeto de Arquitetura I, FAU- UFPA (2018)

A elaboração do partido arquitetônico associada à residência analisada, mostra-se bastante adequada como atividade de síntese, englobando processos e decisões arquitetônicas referendados pelo conhecimento formal da arquitetura, bem como, permitindo o fortalecimento da concepção apoiada em temas que oferecem clareza sobre a cultura arquitetônica construída durante séculos.

O processo de aprendizagem no campo da linguagem e das representações, sendo a decomposição do projeto finalizada com desenho de cada parte analisada, torna possível o entendimento real das operações realizadas entre as partes e o todo, favorecendo as posteriores operações de síntese na elaboração do partido, com acompanhamento individual entre o processo de decomposição arquitetônica e o processo de concepção, relacionando-os.

Além das atividades apresentadas, nas etapas de análise e síntese, os estudantes realizam comentários o aprendizado adquirido durante a análise de projetos residenciais, apresentados no Quadro 2. Definiu-se a escolha aleatória de sete depoimentos dos estudantes, contendo a reflexão dos mesmos ao término das atividades desenvolvidas em sala de aula, análise de projeto arquitetônico de residências, quando ainda cursam a metade do semestre. 


\section{Quadro 2 - Depoimentos dos alunos}

\begin{tabular}{|c|c|c|}
\hline Estudante & Sexo & Depoimentos \\
\hline$A$ & $\mathrm{~F}$ & $\begin{array}{l}\text { No processo de projetar até a construção da obra, há muito mais do que } \\
\text { somente estética e estrutura. Existe o princípio daquele projeto, o ambiente } \\
\text { que o rodeia, como transitar por ele. Aspectos muito mais profundos. }\end{array}$ \\
\hline$B$ & $\mathrm{~F}$ & $\begin{array}{l}\text { A atividade realizada ajudo a expandir a mente, de modo que pude } \\
\text { perceber diferentes formas de organização das construções assim como } \\
\text { inspirações ou temas que geraram a casa, servindo como ponto de partida. } \\
\text { Também foi válido para perceber que todo o projeto se adequa a uma } \\
\text { situação específica e deve atender a proposta sugerida pelo cliente. }\end{array}$ \\
\hline C & $M$ & $\begin{array}{l}\text { Depois dessa atividade percebi e aprendi que na arquitetura há uma } \\
\text { grande diversidade na projetação, na organização de espaços e formas, } \\
\text { estilos utilizados. Cada obra com seu contexto específico, com influência do } \\
\text { arquiteto, do cliente, do meio ambiente, da utilidade e mais...cada arquiteto } \\
\text { tem um jeito específico de pensar e de projetar na arquitetura. }\end{array}$ \\
\hline$D$ & $\mathrm{~F}$ & $\begin{array}{l}\text { A atividade me possibilitou visualizar diferenças e particularidades de cada } \\
\text { projeto, como o pouco conhecimento que já temos de alguns, podemos } \\
\text { identificar as características desses arquitetos dentro de seus projetos. } \\
\text { Também é possível notar que mesmo com suas diferenças, existem ele- } \\
\text { mentos que precisam constar dentro do projeto para gerar funcionalidade. }\end{array}$ \\
\hline$E$ & $M$ & $\begin{array}{l}\text { Interessante ver a variação de interpretação de decomposição de cada } \\
\text { obra. Me mostrou que cada pessoa pode ver algo que não nos atentamos } \\
\text { em observar, com certeza é um ganho de experiência. }\end{array}$ \\
\hline $\mathrm{F}$ & $\mathrm{F}$ & $\begin{array}{l}\text { Da atividade conclui que existe muito nas construção arquitetônica do que } \\
\text { uma fotografia nos mostra. Por meio da decomposição foi possível raciocinar } \\
\text { qual teria sido o ponto de partida do arquiteto para resultar na concepção } \\
\text { final, e ainda ver que por mais que uma casa pareça simples no projeto, tem } \\
\text { todo um pensamento, uma complexidade, uma ideia nada simplória. Assim } \\
\text { como casas que parecem extremamente complexas e tiveram seu ponto de } \\
\text { partida uma ideia mais simples do que aparenta. }\end{array}$ \\
\hline G & $\mathrm{F}$ & $\begin{array}{l}\text { Observando todos os trabalhos, percebi que as diferentes interpretações, } \\
\text { tanto dos temas quanto da própria casa, abrem um maior número de } \\
\text { possibilidades de decomposição e até diferentes resultados dentro de um } \\
\text { mesmo tema ao ser escolhida uma perspectiva diferente ou vista diferente. } \\
\text { Além do que apenas o estudo do arquiteto de determinada casa pode } \\
\text { mostrar de fato o que é certo dentro da decomposição da obra. }\end{array}$ \\
\hline
\end{tabular}

Fonte: Disciplina Projeto I FAU-UFPA (2018).

No segundo semestre do curso de graduação, a mesma turma trabalha teoricamente as analogias e métodos de projeto para que possa explorá-los no exercício projetual, até o anteprojeto de uma passarela para a Universidade Federal do Pará. Utiliza-se como exemplo um resultado do percurso projetual realizado pelos discentes Cássia Baia, Carlos Alexandre Souza, Eduarda Gonçalves, Eduardo Teixeira, Renata Ramos e Katia Padilha, calouros do ano de 2017 da FAU-UFPA, apresentado na Figura 2. 


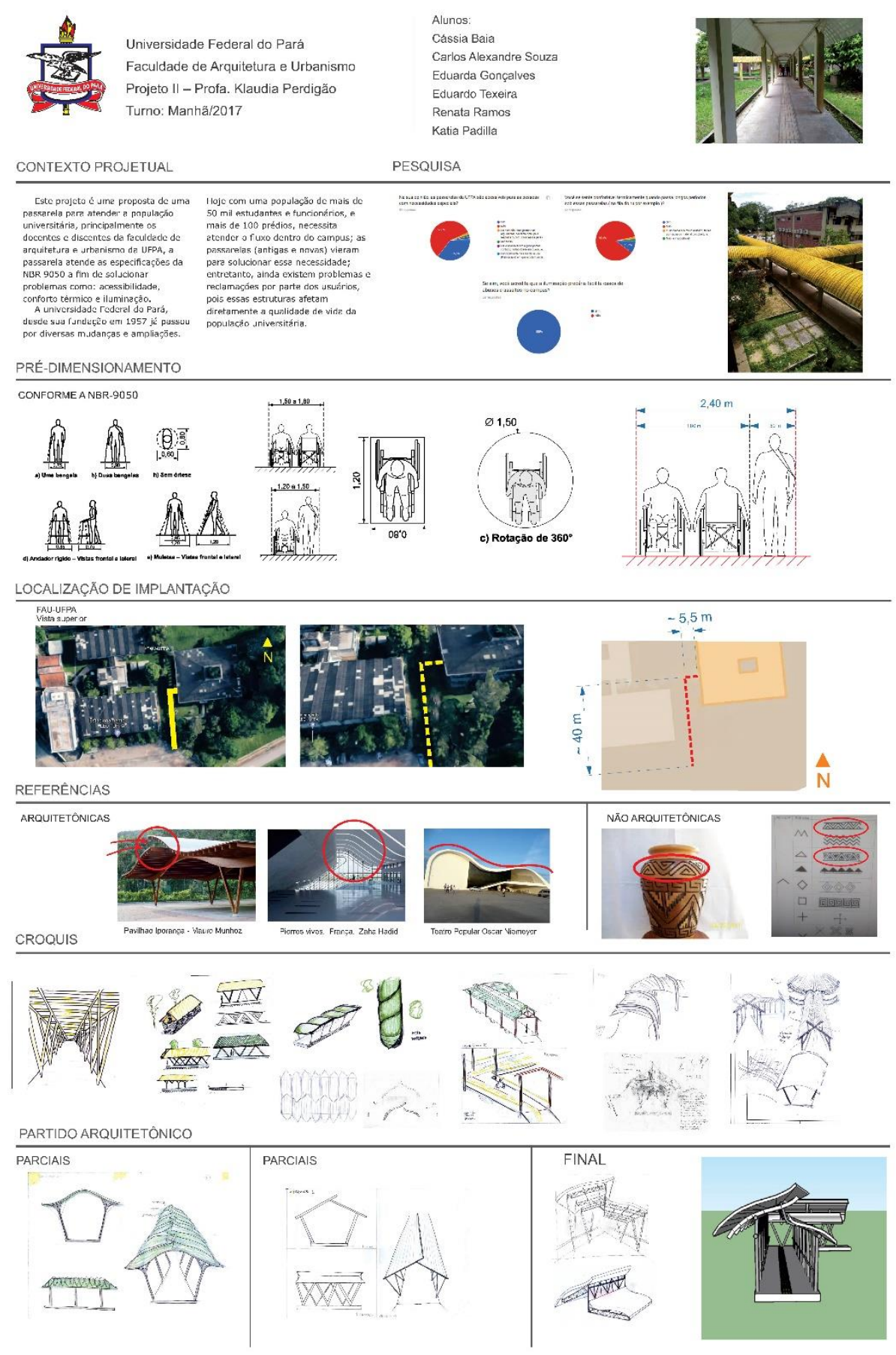

Figura 2 - Percurso projetual para treinamento sistemático de habilidades: síntese Fonte: Disciplina Projeto de Arquitetura II, FAU-UFPA (2017) 
O desenvolvimento da atividade projetual envolve inicialmente a problematização dentro da temática "Passarela UFPA, com discussão de estratégias previstas para pesquisa de projeto, pesquisa bibliográfica e consultas com o usuário final através de questionários e entrevistas. Após a organização dos dados levantados, levantamento físico e discussão com a legislação vigente, os estudantes iniciam o percurso de concepção arquitetônica. Todas as escolhas elaboradas são discutidas nos métodos de projeto sistematizados por Mahfuz (1984).

A motivação para aproveitamento do conhecimento adquirido pela atividade de análise associado ao conhecimento sobre decisão de arquitetos na discussão pelos métodos, revigora o interesse do estudante para as decisões arquitetônicas e também instiga os estudantes para novas possibilidades que a relação entre teoria e prática oferece.

As ideias individuais sobre a gênese do projeto passam por ampla discussão de pontos positivos e negativos no grupo até chegar à escolha de duas propostas finais para aprofundamentos e integrações futuras. Por fim, o grupo de estudantes apresenta a sistematização de todos os passos dados, quando organizam o percurso adotado quando justificam o próprio percurso compreendendo as muitas possibilidades encontradas pelos diversos grupos para solucionar uma problemática comum, valendo-se do repertório arquitetônico formado, das ideias compartilhadas e concepções diversas.

A avaliação das disciplinas PROJETO I e II com base nos resultados obtidos com a finalização das atividades de análise e síntese pelos estudantes, torna evidente a evolução para lidar com problemas inerentes à profissão. Ressaltase a importância da formação de uma base teórico-operativa para a iniciação na atividade projetual, quando o estudante terá contato com a formação de um pensamento em fase de amadurecimento com as experimentações preparatórias para finalização com êxito de atividades acadêmicas para uma resposta consistente às demandas complexas e diversificadas da vida real.

As disciplinas de projeto previstas para o primeiro ano de graduação buscam a instrumentalização do estudante para: interpretação da história sobre os modos de projetar, consideração da relação entre teoria e prática arquitetônica, formação articulada de repertório, filtro operativo para a cultura arquitetônica direcionada ao problema de projeto, abrangência do arquitetônico e do não arquitetônico na concepção, atenção aos vícios de entendimento sobre a profissão, como por exemplo o de que o partido é forma, que arquitetura é resolução geométrica.

\section{CONSIDERAÇÕES FINAIS}

O desenvolvimento do projeto apoiado pelo conhecimento oriundo de teorias da produção arquitetônica, orientadas para o fazer, vem demonstrando uma maior amadurecimento do aparato cognitivo-operativo no apoio à prática arquitetônica.

O pensamento projetual discutido à luz do pensamento de Piaget, amplia o escopo técnico do projeto de arquitetura que passa a transcender a representação geométrica. A adoção de bases assim estabelecidas desde o primeiro ano de graduação leva à disposição do estudante para observação 
de seu próprio processo de concepção, quando já é possível acompanhar e observar o que funciona bem e o que não funciona nos sistemas de representação do espaço.

A preparação de bases metodológicas é tarefa acadêmica sem a qual o projeto arquitetônico não alcança o aprofundamento com a busca de respostas confiáveis, respeitosas e efetivas. O projeto cognitivo é uma estratégia determinante para o aprofundamento de problemas e de respostas apropriadas no âmbito da formação profissional do arquiteto e urbanista, que permite um alinhamento metodológico interessante entre ensino e pesquisa. A trajetória do PPGAU-UFPA mostra a pesquisa em projeto e seus contornos epistemológicos para buscar evidências e dar repostas ao ensino de graduação (PERDIGÃO, 2019).

O conhecimento científico, desse ponto de vista, torna-se central para apoio ao ensino de projeto. Vem se revelando nos últimos 10 anos uma estreita relação entre pesquisa científica e projeto, destacando o papel do conhecimento associado ao desenvolvimento de habilidades e à experiência no ensino de projeto, substituindo um pensamento rígido e fragmentado por outro mais aberto e flexível, fundamental para a criação de um círculo virtuoso combinando produção de conhecimento e ação.

Assim sendo, defende-se a abordagem do processo como método de pesquisa e como estratégia didática no ensino de graduação. Mostra-se adequado ao permitir maior transparência sobre operações ligadas à decisão arquitetônica, ao abordar e dissecar os passos e o raciocínio envolvidos para compor relações e conexões capazes de enfrentar o problema arquitetônico, complexo ou não, com soluções complexas ou não, considerando-se que o problema terá muitas soluções possíveis, infinitas até, porém diretamente associadas à clareza com que o problema é delineado e, consequentemente, resolvido.

\section{AGRADECIMENTOS}

Ao CNPq, à CAPES, à UFPA e um agradecimento especial aos estudantes das turmas de PROJI e II, sem os quais não seria possível problematizar e experimentar caminhos para o aprimoramento do ensino de graduação em arquitetura e urbanismo.

\section{REFERÊNCIAS}

AULT, R. L. Desenvolvimento cognitivo da criança: a teoria de Piaget e a abordagem de processo. Zahar, 1978.

BOUDON, P. Do espaço arquitetural ao espaço de concepção. O lugar do projeto no ensino e na pesquisa em arquitetura e urbanismo. Rio de Janeiro: CONTRACAPA/PROARQ, p. 42-50, 2007.

BRAODBENT, G.; WARD, A.(Eds.). Metodologia del diseño arquitectonico. Barcelona: Gustavo Gili, 1971.

CARPIGIANI, B.; MINOZZI, C. L. O construtivismo piagetiano e o processo de representação no espaço. In: DEL RIO, V.; DUARTE, C. R.; RHEINGANTZ, P. A. (Orgs.). Projeto do lugar: colaboração entre psicologia, arquitetura e urbanismo. Rio de Janeiro: Contra Capa/PROARQ, p. 89-96, 2002. 
CHUPIN, Jean-Pierre. L'analogie ou les écarts de genèse du projet

d'architecture. Genesis (Manuscrits-Recherche-Invention), v. 14, n. 1, p. 67-90, 2000.

CLARK, R. H.; PAUSE, M. Arquitectura: temas de composición/Analysis of precedent. The student publication of the school of design. Mexico: GG., 1983.

COMAS, C. Projeto Arquitetônico: disciplina em crise, disciplina em renovação. São Paulo: Projeto, 1986.

FERNÁNDEZ, R. Inteligencia proyectual. Un manual de investigación en Arquitectura. Buenos Aires: UAI-Teseo, 2013.

FLORIO, W. Análise do processo de projeto sob a teoria cognitiva: sete dificuldades no atelier. Arquitetura Revista, v. 7, n. 2, p. 161-171, 2011.

FRIGERIO, M. C. et al. La enseñanza de lo proyectual: una didáctica centrada en el sujeto. Buenos Aires: Nobuko, 2008.

LARA, F.; MARQUES, S. (Orgs). Projetar: desafios e conquistas da pesquisa e do ensino de projeto. Rio de Janeiro: Editora Virtual Científica, 2003.

MAHFUZ, E. Nada provém do nada. São Paulo, Revista Projeto, n.69, 1984.

MORIN, E. Os setes saberes necessários à educação do futuro. São Paulo: Cortez Editora, 2011.

MUÑOZ, C. A. El proyecto de arquitectura: concepto, proceso y representación. Barcelona: Reverté, 2008.

OLIVEIRA, R. Construção, composição, proposição: o projeto como campo de investigação epistemológica. In: CANEZ, A. P.; SILVA, C. (Orgs.) Composição, partido e programa: uma revisão crítica de conceitos em mutação. Porto Alegre: Livraria do Arquiteto, 2010. p. 33-45.

PERDIGÃO, A.K.A.V.; BRUNA, G.C. Representações espaciais na concepção arquitetônica. In: PROJETAR, 4., 2009, São Paulo. Projeto como investigação: ensino, pesquisa e prática. São Paulo: Alter Market, 2009.

PERDIGÃO, A. K. A. V. Tipo e tipologia na palafita amazônica da cidade de Afuá. V!RUS, São Carlos, n. 13, 2016. Disponível em:

<http://www.nomads.usp.br/virus/virus 13/? sec=4\&item=2\&lang=pt>.

PERDIGAO, A.K.A.V. Teoria da produção arquitetônica. In: CARDOSO, A. C. D. (Org.). Trajetória de pesquisa do Pós-Graduação em Arquitetura e Urbanismo UFPA: 2010 - 2018. Belém, Universidade Federal do Pará, Programa de PósGraduação em Arquitetura e Urbanismo, 2019, 144p. Inclui bibliografias. ISBN 978-85-63728-62-3.Disponível somente online:

<http://ppgau.propesp.ufpa.br/index.php/br/programa/noticias/todas/205ppgau-lanca-e-book>. Acesso em: jun. 2019.

PIAGET, J.; INHELDER, B. La représentation de l'espace chez l'enfant. Paris: PUF, 1977.

REIS, A. T. Repertório, análise e síntese: uma introdução ao projeto arquitetônico. Ed. da UFRGS, 2002.

THORNBERG, J. M. La Arquitectura como lugar: aspectos preliminares de una epistemologia de la arquitectura. Barcelona: Gustavo Gilli, 1974. 